\title{
Host and environment factors for exposure to poisons: a case-control study of preschool children in Thailand
}

\author{
K Chatsantiprapa, J Chokkanapitak, N Pinpradit
}

\begin{abstract}
Objective-To identify host and environment characteristics associated with poison exposure among preschool children in Thailand.

Setting-A matched case-control study in 20 public hospitals in Khon Kaen province.

Methods-Cases comprised 100 consecutive preschool children attending hospital between September 1997 and February 1999 because of reported exposure to a poison. Controls were three children matched by age, sex and area of residence to each case, who had never attended a hospital for this reason. Risk factors were elicited by interviewing the children's caregivers at their homes using a structured questionnaire and analyzed using conditional logistic regression.
\end{abstract}

Results-Number of siblings, whether the child was "medicine eating" and "rushing to explore new objects", the child's activities while the caregiver was working during the daytime, the child's distance from the caregiver while the caregiver was working, whether the child was taken to a non-agricultural worksite, and the number of used containers around the residence, were all statistically significant in univariate analyses. However, when all significant variables were included in a multivariate model, only "medicine eating" and the number of used containers around the residence remained statistically significant.

Conclusion-Attention to "medicine eating" and used containers through increased supervision could be a protective factor against poison exposure for these children. To reduce risk, caregivers should not refer to medicines as foods and used containers should be systematically collected for disposal or recycling.

(Injury Prevention 2001;7:214-217)

Keywords: poisoning in preschoolers; host and environment; risk factors; Thailand

Health

J Chokkanapitak

Faculty of Education N Pinpradit

Correspondence to: Dr Kannikar Chatsantiprapa, Faculty of Pharmaceutical Sciences, Khon Kaen University, Khon Kaen 40002, Thailand kannikar@kku.ac.th
Poisoning is a major health concern in many countries and can be unintentional or intentional. Preschool children need to explore their environment and often put objects into their mouths. Previous studies have reported that characteristics of children and their environment are risk factors for poisoning in this age group.
Children, who have an exaggerated oral trait, ${ }^{1}$ who are aggressive, stubborn, gregarious, or unable to delay gratification, ${ }^{2}$ or who are more reactive to stressful stimuli or experiences, ${ }^{3}$ are more prone to poisoning. Sex and age are also known risk factors. ${ }^{4-7}$

Commonly reported environmental risk factors include mother's lack of knowledge of a poisoning risk, ${ }^{8-10}$ improper storage of toxic substances, ${ }^{11}{ }^{12}$ and improper or insufficient supervision. ${ }^{6}$

These reports reflect the experience in western industrialized countries. Thailand is an agricultural country with a large rural population and a different child rearing culture. Therefore, this study was undertaken to identify the characteristics of host, agent, and environment associated with poison exposure in preschool children in Thailand.

\section{Methods}

This matched case-control study was conducted in Khon Kaen, a central province in northeastern Thailand, the poorest region of the country. Cases were defined as children under 5 brought to any of 20 public hospitals between September 1997 and February 1999 for the treatment of poisoning. Three controls were selected for each case, matched by age (within six months), sex, and residence in the same area as the case, and who had never attended hospital because of poisoning. Data on risk factors were collected by interviewing caregivers of the children using structured questionnaires after verbal informed consent.

Table 1 Characteristics of poisoning incidents

\begin{tabular}{ll}
\hline Variables & $\%$ \\
\hline Child's age (years) & 5 \\
$<1$ & 69 \\
$1-2$ & 26 \\
$3-4$ & 49 \\
Child's gender & 51 \\
Male & \\
Female & 83 \\
Initiator of incident & 13 \\
Child & 4 \\
Child's caregivers & \\
Others: child's friends, other adult, etc & 12 \\
Time of incident (hours) & 28 \\
6.00-8.59 & 4 \\
9.00-11.59 & 27 \\
12.00-14.59 & 23 \\
15.00-17.00 & 6 \\
18.00-20.59 & \\
Other times & 54 \\
Toxic substances involved & 26 \\
Therapeutic drugs & 14 \\
Household chemicals & 6 \\
Agricultural chemicals & \\
Other & \\
\hline
\end{tabular}


Table 2 Characteristics of cases and controls

\begin{tabular}{|c|c|c|}
\hline Variables & Cases (\%) & Controls (\%) \\
\hline \multicolumn{3}{|l|}{ Mean (SD) age of parent (years) } \\
\hline Father & $31.2(6.5)^{\star}$ & $30.1(5.3)^{\star}$ \\
\hline Mother & $27.8(5.9)^{\star}$ & $26.7(5.1)^{\star}$ \\
\hline \multicolumn{3}{|l|}{ Father's education } \\
\hline Primary & 71 & 64.3 \\
\hline Secondary & 17 & 25.7 \\
\hline More than secondary & 12 & 10.0 \\
\hline \multicolumn{3}{|l|}{ Mother's education } \\
\hline Primary & 74 & 71.5 \\
\hline Secondary & 23 & 20.1 \\
\hline More than secondary & 3 & 8.4 \\
\hline \multicolumn{3}{|l|}{ Father's occupation } \\
\hline Agriculture & 45 & 46.5 \\
\hline Labour: daily or permanently employed & 36 & 40.5 \\
\hline Private business & 10 & 5.2 \\
\hline Others & 9 & 7.7 \\
\hline \multicolumn{3}{|l|}{ Mother's occupation } \\
\hline Agriculture & 50 & 49.1 \\
\hline Labour: daily or permanently employed & 19 & 25.2 \\
\hline Housewife & 22 & 17.7 \\
\hline Private business & 8 & 6.2 \\
\hline Others & 1 & 1.7 \\
\hline \multicolumn{3}{|l|}{ Parents' marital status } \\
\hline Living together & 87 & 87.9 \\
\hline Living apart & 13 & 12.1 \\
\hline \multicolumn{3}{|l|}{ Child's primary caregiver } \\
\hline Parents & 83 & 79.5 \\
\hline Grandparents or relatives & 17 & 20.5 \\
\hline \multicolumn{3}{|l|}{ Daytime caregiver } \\
\hline Parents & 52 & 58.0 \\
\hline Grandparents & 34 & 31.6 \\
\hline Other relatives & 7 & 5.2 \\
\hline Nurseries & 7 & 5.2 \\
\hline \multicolumn{3}{|l|}{ Night-time caregiver } \\
\hline Parents & 78 & 76.5 \\
\hline Grandparents or other relatives & 22 & 23.5 \\
\hline
\end{tabular}

${ }^{\star} \mathrm{p}$ Values $=0.04$, all other variables had a $\mathrm{p}$ value $>0.05$

Table 3 Results of conditional logistic regression of host factors ( $p$ value $<0.1$ )

\begin{tabular}{llll}
\hline Significant variables & $p$ Value & Adjusted OR & $95 \%$ CI \\
\hline No of siblings: $>2 v 1$ & 0.099 & 2.37 & 0.85 to 6.62 \\
Medicine eating & $<0.001 \dagger$ & 1.92 & 1.40 to 2.63 \\
Rushing to explore new objects & $0.021 \dagger$ & 1.48 & 1.06 to 2.06 \\
\hline
\end{tabular}

${ }^{\star}$ Ordinal scale variables with four levels (groups) analyzed: (1) absolutely not true, (2) not true, (3) true, (4) absolutely true. †Significant at $\mathrm{p} \leqslant 0.05$.

Interviewers were staff nurses who were trained in data collection and given field practice. Interviewers visited the caregivers of the cases at their homes two weeks after the cases were discharged to conduct an interview. During these visits, interviewers also searched for matched controls in the community at nearby homes and then interviewed their caregivers.

The questionnaire included host, agent, and environment factors. The host factors included general characteristics (for example, rank in family, number of siblings), and habits or characteristics. Examples of habits/characters include "medicine eating", describing a tendency to put medicines into the mouth, and "rushing to explore new objects", describing high curiosity. Agent factors include types of toxic substances in the home, storage practice during use and when not in use, frequency of use, packaging, and disposal practices. Environmental factors included characteristics of parents, child caring, residential area, and attitudes of caregivers. The study was approved by Khon Kaen University's ethics committee.

Risk factors were analyzed using stepwise conditional logistic regression in Stata software $^{13}$ after univariate analysis of each variable. Ordinal variables without an apparent trend related to risk were analysed on a nominal scale. Attitude test variables were on a ratio scale. For each of host, agent and environmental variables, variables with a $\mathrm{p}$ value $\leqslant 0.2$ were included in multivariable analysis. Finally all significant variables with a $\mathrm{p}$ value $\leqslant 0.1$ were analyzed in one multivariable model. In this paper, only host and environment factors are presented.

\section{Results}

Table 1 reports characteristics of the poisoning incidents. Children aged 1-2 years were involved the most frequently, girls more often than boys. Most incidents were initiated by the child. More than half of the substances involved were medicines. Forty six per cent of the cases underwent gastric lavage and for $20 \%$ no treatments were needed $(18 \%$ were observed). There was one fatality.

Table 2 reports the characteristics of the 100 cases and 289 controls. Cases and controls were well matched on a range of demographic factors.

From the multivariable analysis of each factor, the significant variables with a $\mathrm{p}$ value $\leqslant 0.1$ from host and environment factors are presented in tables 3 and 4, respectively and show the variables that are statistically significant. Mean scores of all three categories of the attitude tests (parents-child, mother-father, non-parent caregiver-child relationships) were not different between cases and controls and all were in the positive range. Statistically

Table 4 Results of conditional logistic regression of environment factors ( $p$ value $<0.1$ )

\begin{tabular}{|c|c|c|c|}
\hline Significant variables & p Value & Adjusted $O R$ & $95 \% C I$ \\
\hline \multicolumn{4}{|l|}{ (1) Child care } \\
\hline \multicolumn{4}{|l|}{ Child's activities while caregiver working: } \\
\hline Playing alone $v$ sleep $^{\star}$ & 0.066 & 3.78 & 0.92 to 15.62 \\
\hline \multicolumn{4}{|l|}{ Distance from caregiver while caregiver working: } \\
\hline Too far to hear or see $v$ close enough to hear or see ${ }^{\star}$ & $0.038 \ddagger$ & 3.14 & 1.07 to 9.23 \\
\hline \multicolumn{4}{|l|}{ Child taken to (non-agricultural) worksite†: } \\
\hline (1) never, (2) sometimes, (3) mostly, (4) everyday & $0.016 \ddagger$ & 1.67 & 1.02 to 2.52 \\
\hline \multicolumn{4}{|l|}{ Amount of used containers around the residence: } \\
\hline Plenty $v$ few ${ }^{\star}$ & 0.075 & 2.15 & 0.93 to 4.98 \\
\hline \multicolumn{4}{|l|}{ (2) Attitude tests } \\
\hline $\begin{array}{l}\text { If you could change your past, you would have been singlet: } \\
\text { (1) absolutely not true, }(2) \text { not true, }(3) \text { true, }(4) \text { absolutely true } \\
\text { At significant events your spouse would consult yout: }\end{array}$ & 0.028 & 0.56 & 0.33 to 0.94 \\
\hline (1) absolutely not true, (2) not true, (3) true, (4) absolutely true & 0.097 & 0.49 & 0.20 to 1.14 \\
\hline
\end{tabular}

${ }^{\star}$ Reference level of nominal scale variable.

†Ordinal scale variables with four levels (groups) analyzed.

$\ddagger$ Significant at $\mathrm{p} \leqslant 0.05$. 
Table 5 Results of conditional logistic regression of host and environment factors ( $p$ value $<0.1)$

\begin{tabular}{llll}
\hline Significant variables & $p$ Value & Adjusted OR & 95\% CI \\
\hline $\begin{array}{l}\text { (1) Host factors } \\
\quad \text { Medicine eating*: }\end{array}$ & $<0.001 \ddagger$ & 2.23 & 1.44 to 3.45 \\
$\begin{array}{l}\text { (2) Environment factors } \\
\quad \begin{array}{l}\text { Amount of used containers around the residence: } \\
\quad \text { Plenty } v \text { few }\end{array}\end{array}$ & $0.026 \ddagger$ & 2.36 & 1.11 to 5.02
\end{tabular}

$\star^{\star}$ Ordinal scale variables with four levels (groups) analyzed: (1) absolutely not true, (2) not true, (3) true, (4) absolutely true.

†Reference level (group) of nominal scale variable.

$\ddagger$ Significant at $\mathrm{p} \leqslant 0.05$. never refer to medicines as food but always indicate that medicines must only be taken under adult supervision.

"Rushing to explore new objects" also proved to be a significant risk factor for poisoning exposure. This may be comparable to "unable to delay gratification" described in a previous study. ${ }^{2}$ Potentially toxic substances are normally kept out of reach and sight of children. This generally beneficial practice may have the effect of making these substances objects to explore when the child does see them.

The 2.37-fold increased risk of poisoning exposure when the number of siblings was more than two, compared with only one, may indicate insufficient supervision. When the number of siblings was two, the risk of poison exposure was not raised. Petridou et al reported that when the number of siblings was more than two, the odds ratio (OR) was 1.2 (95\% confidence interval (CI) 0.6 to 2.0 , $\mathrm{p}$ value $0.73) .{ }^{15} \mathrm{~A}$ much higher odds ratio in our study may be due to differences in supervision styles and risks to the safety of children between Thailand and Greece.

Risk of poisoning exposure for children playing alone increased 3.78-fold compared with children sleeping. When children were at distances from caregivers (attendants), too far for the caregivers to hear or see the child, risk of exposure increased 3.14-fold. More frequently being taken to a non-agricultural worksite (OR $1.67,95 \%$ CI 1.02 to 2.5 ) and an increased number of used containers left around the house (OR 2.36, 95\% CI 1.11 to 5.02) increased risks of poisoning exposure. These findings confirm the significance of adequate and appropriate supervision and safe environments in reducing children's risks of exposure to poisoning.

Other studies have reported caregivers' lack of knowledge of the risks of poisoning as a significant risk factor. ${ }^{8-10}$ In this study, parental educational attainment was not statistically different between cases and controls. However, inappropriate disposal or use of empty containers was noted to be common in the study area. Containers were observed to be sometimes washed and reused, or dumped in open pits or put in trash bins. Reuse may increase risk if the container was used for food storage and improper disposal may mean that children can still be harmed by residual contents or the containers themselves. Systematic collection for disposal or recycling would reduce these risks.

Parental separation was not identified as a risk factor in this study, although others have reported high risks (OR 4.7, p value 0.08$)^{4}$. In this study, parents were the major caregivers of their own children and grandparents took their places when the parents were absent. Grandparents still have a significant role in child rearing in Thailand, often with much affection because of their blood relationship. ${ }^{7}$ Compared with the west where non-related baby-sitters are common carers, Thai culture tends not only to stress related caregivers but also to have closer levels of child supervision. ${ }^{16}$ Non-related caregivers have been reported to be associated dies ...." This latter practice is common in Thailand. To reduce this risk, caregivers should 
with increased risk compared with parents and grandparents. ${ }^{17}$ In this study, daytime attendants other than parents and grandparents also increased the risk but the increase was not statistically significant (other relatives: OR 1.51, 95\% CI 0.57 to 3.91, nurseries: OR $1.69,95 \%$ CI 0.57 to 4.97 ).

The two significant items of the attitude tests did not follow prediction. This may indicate problems in collecting data of a sensitive nature. Because poor literacy is common in Thailand's rural areas, the test items were usually read by the interviewers. As a consequence, respondents may have been reluctant to reveal their feelings.

This study's matched design means that age and age related risk factors could not be identified. This may explain why factors identified in other studies of children's poisoning were not found in this study. Nevertheless, this study confirmed that adequate and appropriate supervision are important for child safety and that close supervision by the child's parents and grandparents may protect against poison exposure for preschool children in Thailand. In addition, the findings of this study suggest that efforts should be made to ensure that parents do not tell children that medicine is food and that communities establish systems for safe, periodic disposal of used medicine containers.

The study was supported by the Thai Research Fund (TRF), DIG program, budget year 1997. The first draft of the manuscript was prepared with the help of Mr Bryan Roderick Hamman.
1 Craig JO. Oral factors in accidental poisoning. Arch Dis Child 1955;30:419-23.

2 Olson DK, Kingston R, Hall S, et al. An epidemiological view of poisoning. Vet Hum Toxicol 1985;27:402-8.

3 Wright L, Aslop JA, Garettson LK, et al. The OPQ: a proposed instrument for predicting poisoning accident recurrence in young children. Vet Hum Toxicol 1992;34: 448-52.

4 Beautrais AL, Fergusson DM, Shannon FT. Accidental poisoning in the first three year of life. Aust Paediatr 1981;17: 104-9.

5 Trinkoff AM, Baker SP. Poisoning hospitalisations and deaths from solids and liquids among children and teenagdeaths from solids and liquids among ch

6 Wiseman HM, Guest K, Murray VSG, et al. Accidental poiwoning in childhood: a multicentre survey. 1. General soning in childhood: a multicentre survey.
epidemiology. Hum Toxicol 1987;6:293-301.

7 Chatsantiprapa K, Pattraranit R, Chatsantiprapa P. Preschool childhood poisoning in Khon Kaen Province, Thailand. Vet Hum Toxicol 2000;42:226-7.

8 McIntire MS, Angle CR, Ekin BR, et al. Trends in childhood poisoning: a collaborative study 1970, 1975, 1980. F Toxicol Clin Toxicol 1983-84;21:321-31.

9 Hincal F, Hincal AA, Muftu Y, et al. Pattern of children poisonings in Ankara: a ten year survey. Vet Hum Toxicol 1987; 29(suppl 2):118-20.

10 Govaerts-Lepicard M. Epidemiology in childhood poisoning: implications in prevention planning. $f$ Toxicol poisoning: implications in p

11 Baltimore CL, Meyer RJ. A Study of storage, child behavioural traits, and mother's knowledge of toxicology in 52 poisoned families and 52 comparison families. Pediatrics 1968;42:312-17.

12 Brayden RM, MacLean, WE, Bonfiglio JF, et al. Behavioural antecedents of pediatric poisonings. Clin Pediatr (Phila) 1993;32:30-5

3 Stata Copration. Stata version 6.0. Statistical data analysis. College Station, Texas: Stata Copration, 1984-1999.

14 Dupont WD, Plummer WD. Power and sample size calculation: a review and computer program. Control Clin Trials 1991;11:116-28.

15 Petridou E, Kouri N, Polychronopoulou A, et al. Risk factors for childhood poisoning: a case-control study in Greece. Inj Prev 1996;2:208-11.

16 Amornwiwat S, Khaemmanee T, Thirachitr W, et al. Rearing children in Thai ways. Full research report. Bangkok: children in Thai ways. Full research rep

17 Wezorek C, Dean B, Krenzelok E. Accidental childhood poisoning: influence of the type of caretaker on etiology and risk. Vet Hum Toxicol 1988;30:574-6.

\section{Injury Control: A Guide to Research and Evaluation}

Edited by Frederick P Rivara, Peter Cummings, Thomas D Koepsell, David C Grossman, Ronald V Maier

This book is aimed at epidemiologists, injury control practitioners, program evaluators, trauma surgeons, emergency physicians, and others who wish to conduct injury research or need to better understand published studies. Topics include injury classification, data collection, study design (randomized trials, cohort studies, case-control studies, and others), systematic reviews, prediction rules, outcome assessment, cost effectiveness, and ethical issues in research. The authors are from 12 institutions in five countries. Extensive bibliographies cover the injury literature.

Published by Cambridge University Press

Web address in the UK: uk.cambridge.org

Web address in the USA: www.cup.org

ISBN: 0-521-661528

Hardback, 304 pages, $\$ 95$ (US) 